\title{
Prepared for Anything: The Importance of a Safe and Available Blood Supply during Disasters and other Critical Events
}

\section{LAURIE GILLARD}

\section{LEARNING OBJECTIVES}

1. Recognize the different types of disasters and how they can impact blood availability.

2. Explain the importance of having massive transfusion protocols (MTP) and procedures.

3. Discuss how pathogen reduction technology (PRT) will impact platelet transfusion safety.

ABBREVIATIONS: FDA - Food and Drug Administration, CBER - The Center for Biologics Evaluation and Research, CDC - The Centers for Disease Control and Prevention, TJC - The Joint Commission, CLSI - the Clinical Laboratory Standards Institute, CAP - the College of American Pathologists, TACO - transfusion associated circulatory overload, MTP - massive transfusion protocols, PPH - postpartum hemorrhage, PRT - pathogen reduction technology, PGD - Pan Genera Detection

INDEX TERMS: Disaster management, Emergency management, Massive transfusion, Postpartum hemorrhage, Pathogen reduction technology

Clin Lab Sci 2017;30(4):247

Laurie Gillard, $M S, \quad M L S(A S C P)^{C M} S B B$, Rush University, Chicago, IL

Address for Correspondence: Laurie Gillard, MS, $M L S(A S C P)^{C M} S B B$, Director of the Specialist in Blood Banking Certificate Program, Rush University, Chicago, IL 60612

\section{INTRODUCTION}

Considering the growing scope of disasters in the United States over the past year, hospital based blood banks and transfusion services are required to have an effective emergency management plan. Disaster Preparedness in the Blood Bank will describe how to address this important public health issue. When there are victims of disasters that require transfusion, a current review of the literature for best practices for responding to hemorrhage will be presented in Managing Massive Transfusions in Diverse Patient Populations in a Non-Metropolitan Area. Bleeding patients often require platelets. In Pathogen reduction in platelets: a review of the proposed draft guidance, the author will discuss the recent Food and Drug Administration (FDA) guidance for the use of pathogen reduction technology to improve the safety of platelet transfusions.

\section{Disaster Preparedness in the Blood Bank}

Over the past year, many Americans witnessed firsthand the importance of having a safe, available blood supply following a disaster. During the first nine months of 2017, the United States experienced 15 disasters that claimed 323 lives; these disasters were the result of weather and climate. ${ }^{1}$ Floods, freezing temperatures, severe storms, tropical cyclones, and wildfires can all impact blood availability. In the event of a natural disaster, issues may arise in which blood donors do not donate, donor centers may become damaged, or donor centers may not have staffing to perform the processing and testing of blood; all of which, result in a disruption of the local blood supply.

Hurricanes can disrupt the blood supply for days. In October 2017, as Hurricane Irma moved across Florida, blood centers serving Florida and the majority of the Southeastern United States were forced to temporarily suspend all blood donations for the safety of the donors and donation center employees and because of the massive damage caused by the hurricane. Proactively, affected blood centers will communicate with blood centers from other parts of the country to arrange for shipments of blood.

In the United States, the epidemic of gun violence is 


\section{FOCUS: DISASTER PREPAREDNESS IN THE BLOOD BANK}

another type of disaster that must be prepared for. A not for profit corporation, Gun Violence Archive, located in Washington, D.C., recorded 15,423 gun related deaths and 30,916 injuries in 2017..$^{2}$ Gun violence occurs throughout the U.S. sometimes involving a single victim, other times more. Recently, in Las Vegas, a mass shooting resulted in the death of 58 people and wounded more than 500 individuals. In response to this tragedy, The American Red Cross provided an additional 450 blood products to area hospitals to support the injured victims. $^{3}$

With these statistics, the clinical laboratory must have disaster management strategies in place at all hospitals. The Joint Commission (TJC), the Clinical Laboratory Standards Institute (CLSI), the College of American Pathologists (CAP), and AABB all provide either guidelines or standards to assist the laboratory with disaster management and the AABB Standards for Blood Banks and Transfusion Services, requires an emergency preparedness plan for blood bank and transfusion services. ${ }^{4}$ This plan includes policies and procedures as well as emergency communication plans that must be periodically tested with mock disaster drills throughout the year.

Managing Massive Transfusions in diverse Patient Populations in a Non-Metropolitan Area

What happens when a victim of disaster arrives at the hospital? Depending upon the status of the patient, the patient may or may not require transfusion. For the patient who is hemorrhaging, managing a bleeding patient can literally be a life or death situation. By definition, a massive transfusion is the receipt of 10 or more packed red blood cells within 24 hours. Transfusion of four or more units of red cells within an hour and the anticipation of ongoing transfusions can also be regarded as a massive transfusion. ${ }^{5}$

Recipients of massive transfusions are at risk of electrolyte imbalance, hypocalcemia from citrate toxicity, if the blood is transfused quickly hypothermia. Hemolytic transfusion reactions (possible $\mathrm{ABO}$ incompatibility), febrile non-hemolytic transfusing reactions, allergic reactions and transfusion associated circulatory overload (TACO) are additional risks. The "lethal triad" of trauma consists of hypothermia, acidosis, and coagulopathy. ${ }^{6}$ Advances in trauma research have demonstrated that infusing plasma with red cells as part of the resuscitation has greatly improved patient outcomes.

In order to standardize the response to hemorrhage, many hospitals have implemented massive transfusion protocols (MTP). The MTP in adult trauma situations has been widely studied and published. The ratio most often referenced is one unit of red blood cells: one unit of plasma: one adult dose of platelets (plateletpheresis or whole blood derived). For the majority of trauma patients, this type of MTP is effective. However, with other populations of patients, the "one size fits all" MTP doesn't apply. One example of this is the obstetrical patient. During an obstetrical hemorrhage, also referred to as a postpartum hemorrhage (PPH), pregnant women have specific coagulation needs which are not necessarily addressed by the standardized MTP blood ratio of red cells to plasma to platelets. Because hypofibrinogenemia develops early during a $\mathrm{PPH}$, a predetermined ratio of red blood cells, plasma, platelets, tranexamic acid and fibrinogen should be considered. ${ }^{5}$ For the pediatric population the evidence to support a pediatric MTP is limited. Some pediatric hospitals use MTPs; however, the standard ratio of red cells: plasma has not been well defined. The study of best practices in pediatric trauma resuscitation is ongoing.

Pathogen reduction in platelets: a review of the proposed draft guidance

Having a safe, pure, potent, and effective blood supply is the purview of the U.S. Food and Drug Administration (FDA). The Center for Biologics Evaluation and Research (CBER), within the FDA is responsible for regulating biological products for human use under federal laws. The purpose of CBER is to protect and advance the public health by ensuring that biological products are safe and effective and available to those who need them. ${ }^{7,8}$ Over the past decade, one of the greatest risks of transfusion is bacterial contamination of platelets. Platelets are associated with an increased risk of sepsis and are responsible for more transfusion related fatalities than any other blood product.' The Centers for Disease Control and Prevention (CDC) estimates that approximately 1 in 1,000-3,000 platelet units may be contaminated. Because platelets are stored at room temperature there is a much greater risk for the growth of bacteria. In March 2016, the CBER published a draft 


\section{FOCUS: DISASTER PREPAREDNESS IN THE BLOOD BANK}

guidance, "Bacterial Risk Control Strategies for Blood Collections Establishments and Transfusion Services to Enhance the Safety and Availability for Platelets for Transfusion." ${ }^{10}$ The guidance provides recommendations to control the risk of bacterial contamination of platelets through the use of pathogen reduction technology (PRT).

The FDA has cleared two rapid bacterial detection tests, The BacTx (Immunetics, Inc., Boston, MA) and the platelet Pan Genera Detection (PGD) test (Verax Biomedical, Inc., Worcester, MA) for the detection of bacterial contamination in platelets. The BacTx relies on the detection of peptidoglycan which is found in bacterial cell walls. ${ }^{11}$ The presence of bacteria elicits a reaction, resulting in melanin formation. A photometric change in color represents positive bacterial detection. The Verax test uses an enzyme-linked immunoabsorbent assay to detect the lipoteichoic acid of gram-positive bacteria and polysaccharide antigens specific to gramnegative bacteria. ${ }^{12}$ There are additional benefits to PRT. Studies have shown this technology can inactivate not only bacteria but many types of viruses and parasites as well, lowering the risk of transfusion transmitted infections. With emergent diseases, this technology will help avoid further outbreaks such as the Zika virus transmission. ${ }^{13}$

Protecting public health and promoting transfusion safety are the goals of this focus series. Being prepared for the worst possible situations when patients are at their most vulnerable, to support patient care when catastrophic events occur, and having safe blood products available when needed will save lives. This focus series describes how to create a disaster management plan with a review of regulatory requirements as well as a discussion of lessons learned from past disasters. Highlighting the importance of preparing for and responding to bleeding patients, massive transfusion protocols have been revisited to look at the unique transfusion needs of the adult and pediatric patient population. When patients are bleeding they need platelets. Reviewing the FDA guidance for pathogen reduction technology has opened the door to a much safer platelet product, not only by reducing bacteria but other transfusion transmitted infections.

\section{REFERENCES}

1. 2017 is on track to be a record-setting year for massive natural disasters in the U.S.: Website accessed 12/30/17: https://www.pbs.org/newshour/science/2017-track-recordsetting-year-massive-natural-disasters-u-s

2. Gun Violence Archive: Website accessed 12/30/17: http://www.gunviolencearchive.org/

3. Red Cross Statement on Las Vegas Shooting: Website accessed 12/30/17: http://www.redcross.org/news/press-release/RedCross-Statement-on-Las-Vegas-Shooting

4. AABB Standards for Blood Banks and Transfusion services, 30th edition.

5. Simon TL, McCullough, J,Snyder EL, Solheim BG, Strauss RG. Rossi's Principles of Transfusion Medicine.2016 $5^{\text {th }}$ edition.

6. Technical Manual, $18^{\text {th }}$ edition, AABB Bethesda, MD. Editor Fung M. AABB, 2014.

7. About the Center for Biologics Evaluation and Research (CBER): Website 12/30/17: https://www.fda.gov/AboutFDA/CentersOffices/OfficeofMedi calProductsandTobacco/CBER/default.htm

8. CBER Vision \& Mission: Website accessed 12/30/17: https://www.fda.gov/AboutFDA/CentersOffices/OfficeofMedi calProductsandTobacco/CBER/ucm 122878.htm

9. Bacterial Contamination of Platelets: Website accessed: https://www.cdc.gov/bloodsafety/bbp/bacterial-contaminationof-platelets.html

10. Bacterial Risk Control Strategies for Blood Collection Establishments and Transfusion Services to Enhance the Safety and Availability of Platelets for Transfusion accessed at https://www.fda.gov/downloads/Guidances/Blood/UCM4259 52.pdf

11. Heaton WA, Good CE, Galloway-Haskins R, et al. Evaluation of a rapid colorimetric assay for detection of bacterial contamination in apheresis and pooled random-donor platelet units. Transfusion 2014;54:1634-41

12. PGD Technology: Website accessed 10/01/18: http://veraxbiomedical.com/products/technology.asp

13. Revised Recommendations for Reducing the Risk of Zika Virus Transmission by Blood and Blood Components accessed at https://www.fda.gov/downloads/biologicsbloodvaccines/guidan cecomplianceregulatoryinformation/guidances/blood/ucm 5182 13.pdf 